Article

\title{
Assessing the Value of Urban Green Infrastructure Ecosystem Services for High-Density Urban Management and Development: Case from the Capital Core Area of Beijing, China
}

\author{
Haiyun $\mathrm{Xu}{ }^{1, *}$ and Guohan Zhao ${ }^{2}$ \\ 1 Department of Landscape Architecture, College of Architecture and Urban Planning, \\ Beijing University of Civil Engineering and Architecture, Beijing 102627, China \\ 2 Department of the Built Environment, Aalborg University, Thomas Manns Vej 23, \\ 9220 Aalborg Øst, Denmark; guohanz@build.aau.dk \\ * Correspondence: xuhaiyun@bucea.edu.cn; Tel.: +86-185-1170-9902
}

check for

updates

Citation: Xu, H.; Zhao, G. Assessing the Value of Urban Green

Infrastructure Ecosystem Services for High-Density Urban Management and Development: Case from the Capital Core Area of Beijing, China. Sustainability 2021, 13, 12115. https:// doi.org/10.3390/su132112115

\section{Academic Editors:}

Kevin Muldoon-Smith, Bimal Kumar, Shiv Prasad Singh and Ashish Gupta

Received: 30 September 2021

Accepted: 29 October 2021

Published: 2 November 2021

Publisher's Note: MDPI stays neutral with regard to jurisdictional claims in published maps and institutional affiliations.

Copyright: (c) 2021 by the authors. Licensee MDPI, Basel, Switzerland. This article is an open access article distributed under the terms and conditions of the Creative Commons Attribution (CC BY) license (https:/ / creativecommons.org/licenses/by/ $4.0 /)$.

\begin{abstract}
Urban green infrastructure (UGI) includes green and blue open spaces that provide multiple ecosystem services (ES) and the ecological and cultural benefits for people to hedge the urbanization challenges. In this paper, we assessed the total economic value of ES provided by UGI in the capital core area of Beijing by calculating the value of six types of ES related to high-density urban features: (1) climate regulation, (2) carbon sequestration and oxygen production, (3) water control and conservation, (4) air pollution reduction, (5) noise reduction (6) cultural services through the combination of replacement cost, carbon tax, shadow project, afforestation cost, and market price methods. The results showed that UGI generated economic benefits in the surveyed area of about CNY $¥ 1.56$ billion (USD \$240 million) per year or CNY ¥91.76 (USD \$14) per capita. The largest share of ES came from carbon sequestration and oxygen production, amounting to about $46.32 \%$ of the total ES value. Our findings also revealed that the distribution of ES value patterns varied across communities. This study enhanced the understanding of local UGI and had significant policy implications for future urban sustainable management, both in the capital core area of Beijing and in other high-density urban areas.
\end{abstract}

Keywords: urban ecosystem services; value; urban green infrastructure; high-density urban context; capital core area in Beijing; urban sustainable planning strategy; urban management

\section{Introduction}

Urban green infrastructure (UGI) is widely known as a multifunctional system that involves open green and blue spaces [1-4]. These systems include parks, green rooves, rain gardens, constructed wetlands, detention basins, and so on. At the same time, the multiple functional benefits afforded by UGI include climate adaptation, heat reduction, biodiversity, air quality, and water conservation, as well as more social functions such as increased quality of life through recreation and the maintenance of cultural sites [5-8]. Extensive existing literature from across the globe has shown that Urban Green Infrastructure (UGI) holds the potential to address major challenges of urbanization such as social and cultural loss, climate change, air pollution, landscape fragmentation, and also improves the quality of life for urban residents [9-12]. This is perhaps why the functions and benefits of UGI provided for people have been commonly known as ecosystem services (ES). Certainly, the European Commission (2013) was among the first to address green infrastructure as a strategically planned network that connects various environmental features and provides a wide range of ecosystem services (ES) [13,14].

As a kind of ecological system, and in accordance with the Millennium Ecosystem Assessment (MA) [15-18], the ecosystem services associated with UGI can be further 
divided into provisional services (essential products that support human wellbeing, such as textiles, wood, and freshwater), regulation services (which improve the quality of the natural environment, i.e., air quality, climate, and water recycling), cultural service benefits (emotional benefits such as aesthetic, cultural, and recreational amenities), and other support services (such as biodiversity, atmospheric oxygen production, and soil formation). The ecosystem services generated by UGI are therefore critical for ecological cohesion between a variety of evolving parts and social components, all of which are endemic to urban communities via their provision of human benefits and perpetuation of the sustainable function of urban ecosystems [19]. The valuation of ecosystem services can be a meaningful approach to identify and measure the importance and performance of UGI [20].

According to the international state of the art, despite efforts to include these ES during urban management discussions [21], current initiatives for ES valuation [15,22,23] amid an urban ecosystem have received less attention than others, such as forests, grassland, and wetland ecosystems [21,24]. Besides, some benefits of UGI, which are relevant in an urban capacity, especially in the context of high-density, historical urban areas such as recreational and heritage sites, are not well captured or represented among common ES classification systems [25]. Furthermore, since existing research in an urban context primarily focuses on a single ecosystem service such as air pollution or stormwater management $[26,27]$, there exists a lack of a targeted evaluation system per the coordination of multiple UGI benefits, which creates several barriers to long-term environmental quality and cultural proliferation in a central urban area such as Beijing. Thus, it is valuable to evaluate the ES values generated by UGI in high-density urban areas via holistic ES systems that remain relevant to localized, pre-existing urban features.

According to the Chinese state of the art, UGI has received an increased amount of attention from scholars and decision-makers in China since the early 2000s [28,29] and is also considered one of the most important components to configure an urban ecosystem in 2021 and beyond. At the time, China introduced UGI as a method to improve green, urban, sustainable development as a functional control method that targets city sprawl, mitigates the heat island effect, and enhances the overall urban landscape [28,29]. Existing, China-centric studies may be classified under two main themes (1) green infrastructure (GI) network planning studies through various approaches such as MSPA or cost distance analysis, which present major time and labor commitments, and (2) various evaluations of the features and functions of UGI as a methodology [28]. Among them, the current standards for UGI evaluation research in China mainly focus on fields such as the connectivity of the GI network, resident preferences for GI, and suitability evaluations that include accessibility and ecological sensitivity analyses. However, little research has specifically evaluated the ecosystem service values generated by UGI in the context of central urban areas in China.

It is, therefore, within this context that we performed our study practice within a single high-density urban area in China to assess the economic value of the ecosystem services generated by UGI via a comprehensive ES evaluation system. This study examined the ecosystem service value of provisional services, regulation services, cultural services, and other support services. We developed a case study to explore trends associated with the capital core area of Beijing, one of the most built-up urban areas in China that boasts a high population density. This area just completed its first period of UGI network construction toward urban transformation in 2017 and continues to sustain a master plan for UGI network enhancements, which will span the next five years. As such, the main aim of our study was to identify UGI performance in the capital core area of Beijing at the intersection of human wellbeing.

The implications of our findings could be discussed to further provide spatial planning and management guidance per the development of UGI projects that meet proposed evaluation standards, as well as to measure and refine certain ecosystem service values. The results of this study could support urban decision-makers and planners for a better 
understanding of the performance and contribution factors associated with UGI in the context of the urban ecosystem and also support the identification of potential urban planning and management strategies built from ecological service perspectives.

In short, this paper raises the following research questions:

1. What is the land coverage component of the current UGI in the capital core area of Beijing?

2. What is the generated value of ES based on UGI assessment in the capital core area of Beijing?

3. What is the distribution of the ES value for the current UGI in the capital core area of Beijing?

\section{Materials and Methods}

\subsection{Study Site}

Our study area focused on the "capital core area" of Beijing, which is the capital city of China. Because Beijing is a historical city, the central core of the city, including the Dongcheng and Xicheng districts of Beijing that house 32 communities and span an area of $92.5 \mathrm{~km}^{2}$, is endowed with the full function of the country's political, cultural, and international exchange [30] (Figure 1). The area also serves as a key conservation area for Chinese historical and cultural heritage and offers a window through which to assess the greater urban area in and around Beijing. It has a significant proportion of green space with a green cover rate of 31.95\% [30]. Planning for the current UGI system deployed in the capital core area was initiated in 2004 and included parks and community green spaces to provide various ecosystem service benefits for surrounding residents.

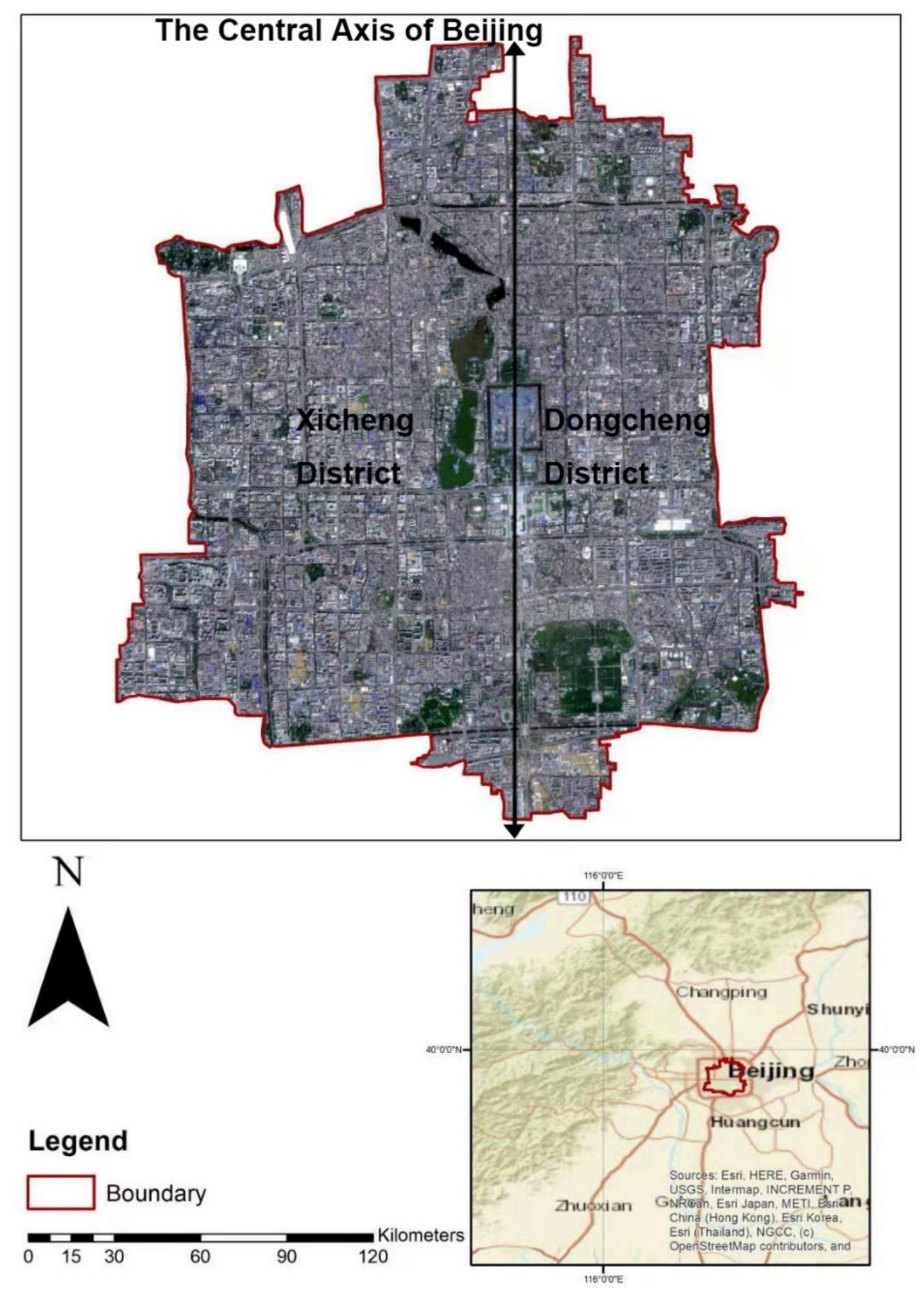

Figure 1. The location of the case study area, the capital core area of Beijing. 
In 2020, the government approved a new master plan for the capital core area of Beijing aimed at the creation of a natural, sustainable living environment that exists in a state of cultural harmony [30]. New UGI will be built to provide public ecosystem services to residents, which means the per capita ES rate will increase from $6.57 \mathrm{~km}^{2}$ at present to $6.8 \mathrm{~km}^{2}$ by 2035 [30]. Local UGI planning protocols for high-density urban areas contain an allocation process of green space resources for surrounding communities. The achievement of justifiable, effective, and strategic green space resource allocation thus demands an improved understanding of local UGI. An evaluation of the true value of ES distribution generated by local UGI will enhance our understanding of UGI performance, which then contributes to future strategic UGI planning. As a result, we examined the ES values provided by the current UGI in the capital core area of Beijing.

\subsection{Data Collection}

We used the land cover dataset from the Finer Resolution Observation and Monitoring of Global Land Cover (FROM-GLC10) for this study, which was interpreted from $10 \mathrm{~m}$ resolution satellite imagery collected via Sentinel-2 in 2017 [31]. Sentinel-2 was launched in 2015 and conducts global observation tasks via high-resolution, multispectral imagery. Thirteen spectral band satellite observation products were delivered from this satellite, including the $10 \mathrm{~m}$ resolution optical and near-infrared bands relevant to our study. A supervised machine learning method was applied to complete the classification task. Thus, both training and validation datasets were collected based on Landsat 8 imagery taken from observations made in 2014 and 2015. To ensure sufficient accuracy, 34,000 training samples and $\sim 14,000$ inter-seasonal observations were included from that year to support the validation task [32].

Here, a random forest classifier of 200 trees was used to interpret our multi-dimensional dataset, specifically to pursue high computational performance. Meanwhile, the collected global digital elevation data from the Shuttle Radar Topographic Mission (SRTM) was included to distinguish between different land cover types (e.g., forest, grassland, and shrubland). In benchmarking these results against the validation dataset, the overall accuracy of this land cover classification reaches $72.76 \%$. In contrast to other alternatives (e.g., the FROM-GLC30), the FROM-GLC10 provides a better way to distinguish between shrub and grassland, which is essential for the ES computations used in this study. Furthermore, fewer misclassifications are involved, particularly for differentiation between the shaded areas and the waterbody, which are known for common classification errors in dense urban areas. Hence, we believe that this land cover dataset delivers high resolution and sufficient classification accuracy for our ES computation study per the capital core area of Beijing.

Nevertheless, public park areas most likely include more than one type of land cover class (i.e., forest and impervious area), which can be difficult to trace merely through remote sensing technologies. As such, we manually traced the park areas based on satellite images taken from the Sentinel-2 satellite for the computation of the cultural ecosystem service.

\subsection{Data Analysis}

We performed our study referring to Costanzo's ecosystem services calculation method [33], which built a basic research framework for ecosystem service value assessments as follows.

The technical route was as follows: first, in accordance with certain standards, such as human development, the utilization of land, or the natural condition of the ecosystem, the ecosystem area proposed in the study was classified into the various ecosystems with different land covers according to different calculation methods. From there, it was possible to calculate the unit area capital of various types of ecosystem services, and finally, 
to calculate the total capital and summarize the total capital structure of the table. The total value of regional ecosystem services across our target area was calculated as:

$$
\mathrm{R}=\sum_{j=1}^{m} \sum_{i=1}^{n} V_{i j} A_{i}
$$

where $\mathrm{R}$ is the total value of regional ecosystem services, Vij means the unit value of the $j$-th ecological system service function within the i-th ecological system, and $\mathrm{A}$ is the area of the $i$-th-type ecosystem.

According to the multiple economic and cultural functions associated with UGI, as well as the perspectives mentioned in China's 2020 master plan for the capital core area of Beijing [30], we selected the following six economic services for our evaluation: (1) climate regulation, (2) carbon sequestration, (3) water control and conservation, (4) air pollution reduction, (5) noise reduction, and (6) cultural services. We aim to calculate the economic value of these six economic services to evaluate the status quo of UGI within the capital core area of Beijing.

Appendix A shows the calculating process, basic parameters, and data sources we used to estimate the economic value of associated ES and their evaluations. Our study intent was to calculate the current benefits of UGI overall and did not involve a historical comparison nor value-added calculations.

\subsubsection{Value of Climate Regulation Benefit}

As urban heat island (UHI) intensity can negatively affect human health and wellbeing, especially in summer, the climate regulation benefits provided by UGI are important to improve and sustain urban wellbeing. It is widely established that UGI could reduce local UHI levels [34,35], while UGI-associated vegetation has been shown to increase evapotranspiration and shading and reduce radiation, absorption, and the amount of heat stored within urban surfaces [34,35]. Thus, UGI and its surrounding area often have lower temperatures than other urban contexts [35]. In the summertime, the cooling effect produced by UGI may therefore directly reduce high energy use from air conditioners. Here, evaluations about climate regulation value could then be replaced by estimates that consider the reduced cost of air conditioning.

In our study, a replacement cost method (RCM) was deployed to evaluate the climate regulation benefit provided by UGI within our target area. The RCM looks at the cost of replacing a damaged or lost asset and uses this cost as a partial proxy or measure of its value [36]. Scholars have long addressed the main advantages of this method, such as easily obtainable information about cost or reduced time to valuation estimate [37]. Recently, the RCM has received increased attention across various studies (e.g., in forest and wetland ES assessments), which have been able to prove its applicability when estimating the value of regulation services like climate regulation and air pollution reduction [37,38]. Existing studies have similarly supported the RCM's potential as a useful heuristic tool that provides valuable information to policymakers $[37,39]$. When we look at the numbers, prior studies have also identified the temperature adjustment effects of a big tree, which, over $24 \mathrm{~h}$, is equal to $1046 \mathrm{KJ}$. This level of energy consumption is equivalent to ten air conditioners working for $20 \mathrm{~h}$ each, estimating a per unit power consumption of $0.86 \mathrm{kWh} /$ unit [40]. The average electricity bill, according to the average standard of Beijing's recorded electricity charges, is calculated at CNY0.60/kWh, or CNY0.516/(h-unit).

When we then account for the urban forestland planting standard in Beijing [41], we see more than two hundred trees planted in urban forestland per hectare. As mentioned above, the resultant evapotranspiration, shading, and mitigation of urban heat radiation from these trees produces the cooling effect found with UGI. Thus, such cooling effects may further be influenced by the morphological, physiological, and biochemical features (such as canopy size, leaf density, and age) of these trees. For instance, the cooling effect would not be so large if trees were small, sickly, or unprotected. To have enough leaves for 
evapotranspiration, shading, and heat radiation mitigation, we calculated that, on average, 100 trees per hectare are needed to effectively contribute to cooling effects, and to reduce local temperatures known to Beijing's urban forestry centers, as referred to in previous research [40]. Finally, we calculated air conditioning time as a period of 60 days per year, to which the annual benefit of climate regulation was calculated in Appendix A, Table A1 Equation (1).

\subsubsection{Value of Carbon Sequestration and Oxygen Production}

Central Beijing is a highly dense, built-up area of the city, where a large amount of $\mathrm{CO}^{2}$ emissions stem from energy production sources such as high population and urban transportation. In this context, UGI plays an irreplaceable role in maintaining the dynamic balance between $\mathrm{CO}^{2}$ and $\mathrm{O}^{2}$ in the surrounding urban atmosphere [35]. In short, the carbon sequestration capacity of the average UGI can be linked to positive increases in vegetation biomass [35].

In this study, the carbon tax and market price method were used to estimate the service value of carbon sequestration and oxygen release for UGI. Via the carbon tax method, we establish the quantity relationship of fixed carbon and oxygen release from UGI-associated vegetation and then multiply that by the carbon emission charges found per national and international standards, all to determine the value of carbon sequestration. The carbon tax method is widely regarded as the optimal approach when directly estimating ecosystem service values for carbon sequestration and oxygen release [42,43]. Furthermore, the market price method is commonly applied to quantify direct production values based on commercial market price trends [42]. This approach has therefore been addressed as a suitable avenue for the buying and selling of valuable ecosystem services within various commercial markets thanks to widespread data availability [44]. Certainly, it relies on observed standard data, commonly accepted cost and price measures, or tangible consumer preferences. Per the evaluation of oxygen release metrics, oxygen was quantified as the direct product of UGI, which is then multiplied by the cost of oxygen production to assess service value.

In terms of carbon sequestration, measures begin by noting that each hectare of forest can absorb up to and beyond $1000 \mathrm{~kg}$ of $\mathrm{CO}^{2}$ per day. The efficiency of forestland absorption for $\mathrm{CO}^{2}$ is, therefore, $365 \mathrm{t} /\left(\mathrm{a} \cdot \mathrm{hm}^{2}\right)$; similarly, the efficiency of grassland absorption for $\mathrm{CO}^{2}$ is $131.4 \mathrm{t} /\left(\mathrm{a} \cdot \mathrm{hm}^{2}\right)$ [36]. The economic value of the $\mathrm{CO}^{2}$ absorption function can be measured per ecosystem unit via carbon tax methods [42]. According to the China carbon pricing survey from ICF, the carbon tax price in China was about CNY $¥ 49 / \mathrm{t}\left(\mathrm{CO}^{2}\right)[45]$ at the time of this study's publication.

For oxygen production benefits, each hectare of broad-leaf forest can release $>2750 \mathrm{~kg}$ of oxygen per day, while the average grassland area releases up to $0.01 \mathrm{~kg}$ of $\mathrm{O}^{2}$ per hour. According to previous literature, the value of oxygen was regarded as the cost of producing oxygen according to industry standard, i.e., cooling air to the point of liquefaction and then using hot air to remove other gases via their different boiling points thus, resulting in pure oxygen. The cost to produce oxygen per industry standards in China is calculated at CNY $¥ 4000 / \mathrm{t}$, whereas the value of oxygen released via woodland areas is CNY $¥ 821,250 / \mathrm{hm}^{2}$. Thus, the fiscal value of grassland oxygen release is CNY $¥ 262.8 / \mathrm{hm}^{2}$ [36].

Finally, we summed these two benefits above and calculated the annual value of carbon sequestration and oxygen production as Appendix A Equations (2.1)-(2.2).

\subsubsection{Value of Water Control and Conservation}

Existing research has addressed UGI's contribution to water management efforts through runoff prevention and stormwater recapture to facilitate flooding where rain and natural earth filtration occurs-both of which also benefit groundwater supply and water reuse for activities such as landscaping [46]. As such, we used the shadow project method (SPM) to evaluate the ES on water control and conservation provided by UGI. Should the water control and conservation functions of UGI degrade, the SPM would 
be needed in response to absorb the floodwaters, with flood control measures ultimately required. To achieve this, the cost of the flood control project per year was annualized via the amortization of the capital cost to arrive at an annual value for water control and conservation benefits. Thus, SPM is also an implicit form of market price, defined as the marginal price that society invests on the non-marketed ES through the construction of these projects [42,43]. Scholars have already addressed its applicability for assessing the value of water control and storage $[38,39,42]$. We thus performed an SPM analysis to assess the value of water control and conservation per the ES provided by UGI.

Per the Beijing Hydrological Bureau, the average annual precipitation in the flood season in Beijing is $547.5 \mathrm{~mm}$ [47]; the national flood control project construction investment is estimated to cost CNY $¥ 0.67$ per $1 \mathrm{~m}^{3}$ of storage capacity [48]. The areas of wetland, water, and forest are regarded as the primary UGI for water control. We performed the calculations for the annual value of water control and conservation benefit as Appendix A Equation (3).

\subsubsection{Value of Reducing Noise}

The existing literature addresses the function of vegetation in the absorption and insulation of noise, while urban greening has a certain commonality when it comes to noise attenuation [49]. The value of the noise reduction provided by UGI is directly related to the performance of any given forest on its own [50]. We thus used the afforestation cost method to evaluate the ES value of noise reduction. To be clear, the afforestation cost method refers to the construction cost of the forest area, which has the capacity to reduce an equal amount of noise-enough to replace the values of other (more costly) means of urban noise reduction $[40,42,48]$. Currently, the afforestation method is a widely used approach to estimate the value of forest ecosystems at the axis of noise reduction and is based on a $15 \%$ afforestation cost $[40,42]$, which is determined by the average afforestation cost multiplied by the volume of mature forest per unit area, and total forest area. According to the Beijing Park bureau, the average afforestation cost is approximately CNY $¥ 300.03 / \mathrm{m}^{3}$, while the volume of mature forest per unit area is $80 \mathrm{~m}^{3} / \mathrm{hm}^{2}$. Appendix A Equation (4) shows the detailed calculation process.

\subsubsection{Value of Reducing Air Pollution}

Many research publications have revealed the function of UGI as it relates to air pollution reduction, particularly sulfide and nitride present in the air, at the intersection of absorption range and plant resistance $[26,40,48]$. Our study also utilizes the replacement cost method to evaluate the fiscal and economic value of reduced air pollution. As mentioned in the previous paragraph, RCM was claimed as an applicable approach to assess regulation services like the regulation and reduction of air pollution. As such, we used the cost evaluation method to measure $\mathrm{SO}^{2}$ and $\mathrm{NOx}$, and to replace the value of air pollution reduction.

The value of reducing air pollution can therefore be summarized as follows:

1. The value of $\mathrm{SO}^{2}$ absorption: The $\mathrm{SO}^{2}$ absorption capacity of broad-leaved forest is $88.65 \mathrm{~kg} /\left(\mathrm{hm}^{2} \cdot \mathrm{a}\right)$ [40], the average $\mathrm{SO}^{2}$ absorption capacity of coniferous forest is $215.60 \mathrm{~kg} /\left(\mathrm{hm}^{2} \cdot \mathrm{a}\right)$, the average $\mathrm{SO}^{2}$ absorption capacity of the two is $152.125 \mathrm{~kg} /\left(\mathrm{hm}^{2} \cdot \mathrm{a}\right)$, while the cost of $\mathrm{SO}^{2}$ governance is CNY $¥ 3000$ per ton [40].

2. The value of NOx absorption: At present, the cost to deploy denitrification treatments to combat automobile exhaust is approximately CNY $¥ 16,000$ per ton. $1 \mathrm{hm}^{2}$ of forest land can absorb $380 \mathrm{~kg}$ of nitrogen oxide per year.

3. The value of retention, filtration, and dust reduction for floating dust: The dust retention capacity of a coniferous forest is $33.2 \mathrm{t} / \mathrm{hm}^{2}$, the dust retention capacity of a broad-leaved forest is $10.11 \mathrm{t} / \mathrm{hm}^{2}$, the average is $21.65 \mathrm{t} / \mathrm{hm}^{2}$, and the dust reduction cost is CNY $¥ 170 / \mathrm{t}[40]$. 
Then, the annual benefit of reducing air pollution could be calculated as the sum of the value of $\mathrm{SO}^{2}$ absorption, NOx absorption, and dust reduction, which is shown in Appendix A Equations (5.1)-(5.3).

\subsubsection{Value of Cultural Service (CES)}

As we mentioned in the introduction, the cultural services (CES) provided by UGI are largely determined by people's subjective perceptions and needs, and significantly affect the improvement of human wellbeing per physical and mental health and spiritual culture [15]. According to studies on the topic of urban green infrastructure, such projects provide a myriad of cultural services and values, from recreation and tourism to environmental appreciation, education, and the fulfillment of spiritual needs [51-53]. For instance, the scenic aspects of UGI provide pleasant aesthetics, motivate intellectual stimulation, and add a real human element to urban spaces meant for tourism and leisure activities. The biodiversity inherent to UGI establishes a critical platform for environmental education. Moreover, some UGI, such as the renowned glory of the forests surrounding Tiantan Temple in Beijing, have the real potential to become recognizable cultural heritage sites in the city. UGI promotes social activities like environmental discussions, volunteer service, and wilderness hobbies such as fishing, bird watching, and horticultural therapy. From these, residents benefit from an increased sense of belonging, a tangible group identity, improved physical and mental health, and increased social relationships. Such results are also regarded in the literature as the CES that result from responsible UGI $[15,53]$. Still, since the cultural service value of a given ecosystem is non-material and non-consumable [44], it is sometimes difficult to quantify its true value. In our study, we thus directly use the CES value of each green space type across Beijing in accordance with category denominations made by Li in 2019 [54]. That study summarized green spaces in Beijing as mainly providing the CES benefits of recreation, tourism, aesthetics, and education [54]. According to such findings, the average CES value generated by green spaces in Beijing is CNY $¥ 19.10 / \mathrm{m}^{2}$. Among these spaces, the main inner-city park in Beijing provided a CES value of CNY $¥ 27.24 / \mathrm{m}^{2}$, while most other public green spaces across the city averaged CNY $¥ 16.70 / \mathrm{m}^{2}$. [54] Because of increased data availability, we regarded CES as a direct product of UGI per accepted and standard market values in Beijing. We then performed the market price method to evaluate total CES benefit via measures of the various CES provided by each type of green space, multiplied by the total area of each green space on its own. Results may be found in Appendix A-Equation (6), which details the calculation process.

\section{Results}

\subsection{Urban Green Infrastructure (UGI) in Central Beijing}

Our first step was to measure the land cover outcome for the capital core area of Beijing. The UGI ecosystem in that area includes 790.26 ha of forest land, 0.06 ha of shrubland, 26.39 ha of grassland, 5.47 ha of wetland, and 416.14 ha of bodied water. "Forest land" areas in this study, therefore, refer to the sum of all forest areas and shrubland. We also included green space areas and flower beds that occupy either side of a road in our "grassland" ecosystem categorization. Our result is the total land cover metric for UGI within the capital core area of Beijing (Figure 2). The UGI in central Beijing has been classified into the park and other public green spaces, whereas according to the yearbook from the Beijing garden bureau, the total area of the park system there is $1138.1 \mathrm{ha}$, and the total area of the remaining other public green space is 136.4 ha. 

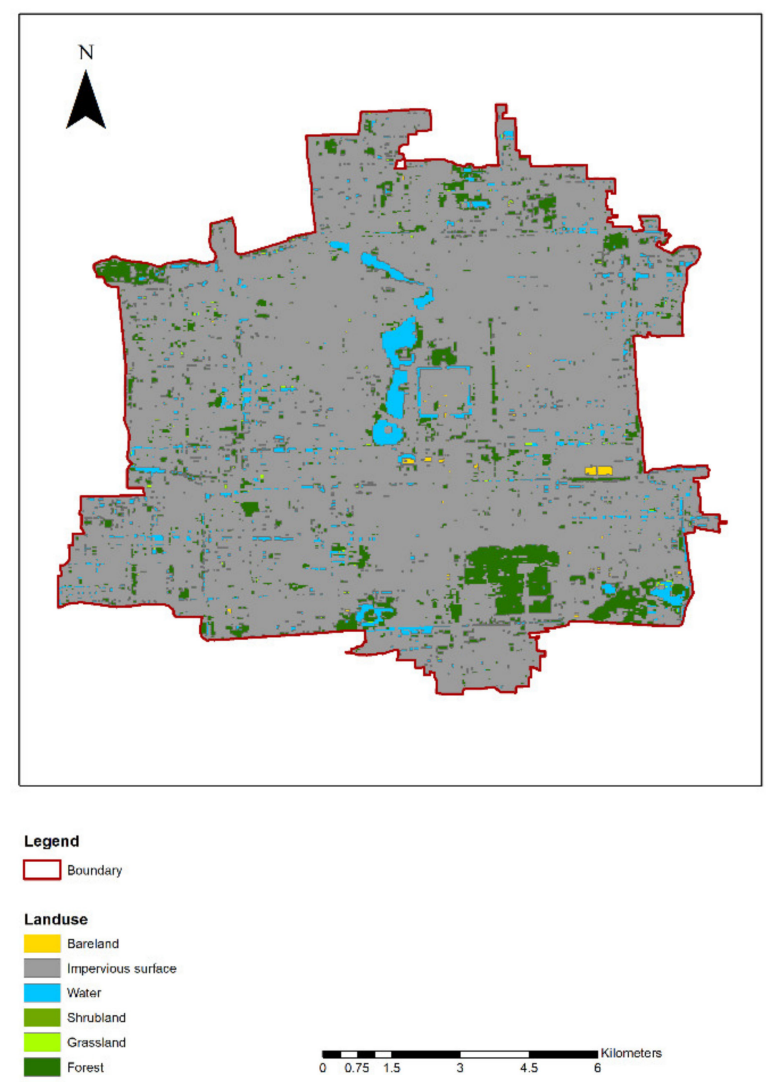

Figure 2. The land cover of UGI within the capital core area of Beijing.

\subsection{The ES Value of Urban Green Infrastructure (UGI) in Central Beijing}

We determined the ES value generated by UGI in the core of Beijing based on the outcome area of various UGI land cover types. Evaluation results were as follows:

1. Climate regulation benefit: The total climate regulation value of forest land was estimated to be CNY $¥ 490,319,677$ (USD $\$ 75,433,796$ ) per year, or CNY $¥ 619,200$ (USD $\$ 95,251.54) /$ ha / year via replacement cost calculations.

2. Carbon sequestration and oxygen production: Based on afforestation calculations and via the market price method, we estimated that the total value of carbon sequestration provided by UGI in our case study area is CNY $¥ 74,207,632$ (USD \$11,416,559) per year, or CNY $¥ 125,708$ (USD 19,350)/ ha/year. The total value of oxygen production is CNY $¥ 649,064,052$ (USD $\$ 99,856,008$ ) per year, or CNY $¥ 821,512$ (USD $\$ 126,386$ ) $/$ ha/year. Thus, the total impact value of UGI on carbon sequestration and oxygen production is CNY $¥ 723,271,684$ (USD $\$ 175,623,890$ ) per year and CNY $¥ 947,220$ (USD $\$ 145,726) /$ ha/year;

3. Water control and conservation: The total value of the water control and conservation benefit provided by UGI was estimated through the shadow project method. Urban green infrastructure produced a CNY $¥ 4,445,717$ (USD $\$ 683,956$ ) per year, or a CNY $¥ 3668.3$ (USD \$564.30)/ha/year value at the intersection of water control and conservation;

4. Noise reduction: Based on the afforestation method, the total value of the noise reduction variable for all UGI was estimated to be CNY $¥ 2,845,182$ (USD $\$ 437,720$ ) per year, or CNY $¥ 3600$ (USD \$554)/ ha/year.

5. Air pollution reduction: We assessed air pollution levels for sulfide, nitride, and dust. The total value of absorbed $\mathrm{SO}^{2}$ by forest land was estimated to be CNY $¥ 361,575.20$ (USD $\$ 55,626.95$ ) per year, or CNY $¥ 436$ (USD \$70.18)/ha/year. The value of NOx absorption was estimated to be CNY $¥ 4,805,196$ (USD \$793,261) per year, or CNY $¥ 6080$ (USD \$935.38)/ha/year. The value of dust retention, filtration, and reduction 
for floating dust is CNY $¥ 2,908,803$ (USD $\$ 447,508.20$ ) per year, or CNY $¥ 3680.50$ (USD \$566.23)/ha/year. The total ES value of UGI at the intersection of air pollution reduction was CNY¥8,075,575 (USD \$1,242,396) per year.

6. Cultural service: Based on the CES value inherent to many green space types in Beijing (Li, 2019), we estimated the total value of UGI for the capital core area of Beijing; results indicate an ES value of CNY $¥ 332,194,392$ (USD \$51,106,830) per year, or CNY $¥ 190,000$ (USD $\$ 29,230.77$ )/ha/year-this according to the green space classifications from the Beijing Garden Bureau.

Next, we estimated the total economic value of the ecosystem services (ES) that UGI in the capital core area of Beijing generates. Results and percentages may be seen in Table 1 below.

Table 1. The total value of ES provided by UGI in the capital core area of Beijing.

\begin{tabular}{|c|c|c|c|c|c|c|c|}
\hline Type of ES & $\begin{array}{c}\text { Climate } \\
\text { Regulation } \\
\text { Benefit }\end{array}$ & $\begin{array}{c}\text { Carbon } \\
\text { Sequestration } \\
\text { and Oxygen } \\
\text { Production }\end{array}$ & $\begin{array}{l}\text { Water Control } \\
\text { and } \\
\text { Conservation }\end{array}$ & $\begin{array}{l}\text { Reduce } \\
\text { Noise }\end{array}$ & $\begin{array}{l}\text { Reduce Air } \\
\text { Pollution }\end{array}$ & $\begin{array}{l}\text { Cultural } \\
\text { Service }\end{array}$ & Sum \\
\hline $\begin{array}{c}\text { Value } \\
\text { (CNY } ¥)\end{array}$ & $490,319,677$ & $723,271,684$ & $4,445,717$ & $2,845,182$ & $8,075,575$ & $332,194,392$ & $1,561,152,227$ \\
\hline
\end{tabular}

In sum, the total established value of central Beijing's UGI resulted in a CNY $¥ 1.56$ billion (USD \$240 million) annual ecosystem service value. The highest economic benefit provided by UGI in the core capital region of Beijing was generated from carbon sequestration and oxygen production $(46.32 \%$ of the total), followed by climate regulation benefits $(31.41 \%)$, and cultural service benefits $(21.28 \%)$. When we consider that Beijing sustains a population of 1.7 million residents within the core area alone, the per capita value is CNY $¥ 91.76$. When we then refer to the current UGI area targeted by our study, and from the above evaluations, we may conclude that the ecological service functions of UGI in the capital core area in Beijing produce significant ecological and economic benefits.

\subsection{The Distribution of ES Value of Existing Urban Green Infrastructure (UGI) in Central Beijing}

This article takes the established ES evaluation from the above investigation and translates it into a spatial pattern that is based on the UGI patterns of different communities. The established spatial pattern further analyzes the characteristics of the distribution of ES value for existing UGI in the capital core area of Beijing. In general, the various economic services (and therefore their benefits and functions) were not equally provided across the entire study area, as shown in Figure 3.

We classified the 32 communities into seven levels by the total value of their ES (Figure 3A-G). Our results indicate the Tiantan community with the largest urban park, the Temple of Heaven historical park, generated the greatest climate regulation value (CNY $¥ 102,594,512$ /year) (Figure 3B), carbon sequestration, and oxygen production value (CNY $¥ 151,453,951 /$ year) (Figure 3C), noise reduction value (CNY $¥ 1,656,888 /$ year) (Figure 3E), air pollution reduction value (CNY $¥ 1,692,784$ /year) (Figure $3 \mathrm{~F}$ ), and cultural service value (CNY $¥ 56,267,225 /$ year) (Figure 3G) of all 32 communities in our case study. In fact, this community had the largest cultural service value provided by UGI across our whole study. The Tiantan community values were closely followed by the Longtan, Zhanlanlu, and Hepingli communities in the northern region (Figure 3A).

For the ES values of water control and conservation (Figure 3D), the Tiantan community also contributed the highest value in our study, with an outcome worth CNY $¥ 617,270$ /year. These results are closely seconded by the Shichahai community, which possesses a water control and conservation ES value of CNY $¥ 399,605$ /year and boasts the largest water and wetland area in our case study (Figure 3D). By contrast, the Jiaodaokou community adjacent to the central axis of Beijing saw the lowest values from their UGI for climate regulation (CNY $¥ 483,936 /$ year), carbon sequestration and oxygen production 
(CNY $¥ 714,357 /$ year), and noise reduction (CNY $¥ 2813 /$ year) and air pollution reduction (CNY $¥ 7984 /$ year).

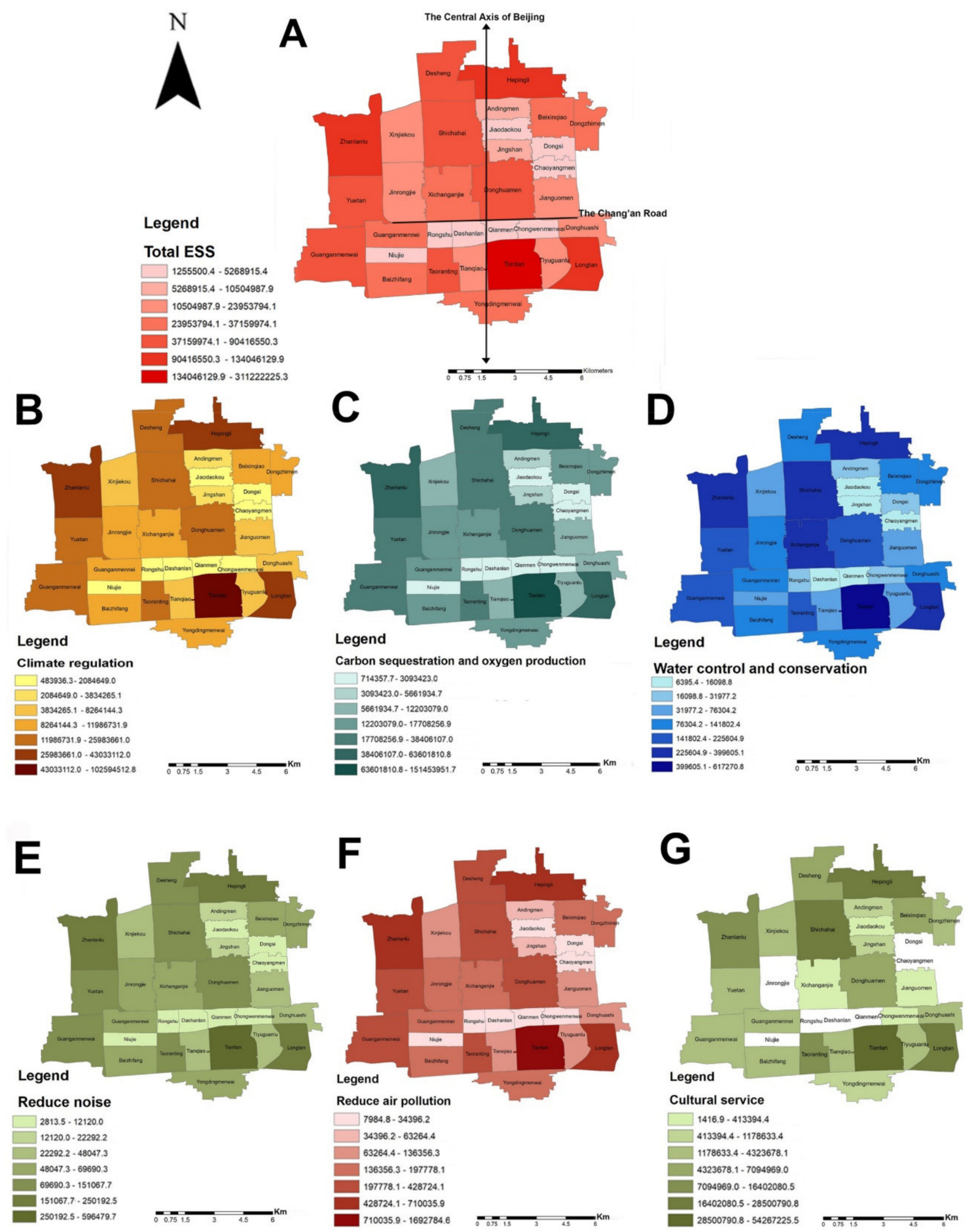

Figure 3. The distribution of ES value of existing Urban Green Infrastructure (UGI) in the capital core area of Beijing. (A) The distribution of total ES value of UGI; (B) The distribution of climate regulation value of UGI; (C) The distribution of carbon sequestration and oxygen production value of UGI; (D) The distribution of water control and conservation value of UGI; (E) The distribution of reducing noise value of UGI; (F) The distribution of reducing air pollution value of UGI; and (G) The distribution of cultural service value of UGI.

Our study also indicated that communities along the Chang'an Road (Rongshu, Dashanlan, Qianmen, Chongwenmen) bear similarly poor performance when it comes to 
the ES values of climate regulation ( $<\mathrm{CNY} ¥ 2,084,649 /$ year), carbon sequestration, and oxygen production ( $<\mathrm{CNY} ¥ 3,093,423 /$ year), noise reduction $(<\mathrm{CNY} ¥ 12,120 /$ year), and air pollution reduction ( $<\mathrm{CNY} ¥ 34,396 /$ year). Among these communities, the Dashilan community also had the lowest water control and conservation values (CNY ¥6615/year), a result nearly the same as the Jiaodaokou community (CNY ¥6396/year).

In sum, the overall distribution of UGI-generated ES values for the capital core area of Beijing is unequal between different communities. The variable nature of this distribution could provide a new basis on which decision-makers and urban planners improve their personal understanding of the local impacts of UGI. It also has the potential to aid in the achievement of justifiable, effective, and strategic green space resource allocation.

\section{Discussion}

Our analysis revealed that the urban green infrastructure (UGI) located in the capital core area of Beijing provides an ecosystem service (ES) value worth an estimated CNY $¥ 1.56$ billion annually. This result happens to be the first evaluation that targets the specific ecosystem service value of established UGI projects in Beijing. Individual benefits to locals in the area amounted to an estimated CNY $¥ 918.32$ per household per year, where previous studies in this niche studying China saw only CNY $¥ 295.36$ per year as recently as 2010 [55]. Our results further determined that the ES values generated by existing UGI in central Beijing are higher than China's national standard.

Existing literature on ES evaluations mainly focused on large-scale studies at the national and regional levels [54-56]. When it comes to ES evaluations in an urban context, distinct communities and districts are rarely considered. In China, for instance, Ouyang conducted a study to evaluate the ES of China's terrestrial ecosystem and its ecological and economic value [56]. That study combined China's national conditions and comprehensively used ecological and economic methods to analyze the value of China's terrestrial ecosystem. Although it was widely regarded as a classic and effective method per the evaluation of ES along with various ecosystem types, the cultural service dimension relating closely to individual wellbeing in an urban context often goes unconsidered when evaluating economic value. Aside from that, the provisional services were reconsidered for a high-density urban context that does not contain productive farmlands nor forestland. Thus, some parameters in our calculation method have been adjusted in view of our case study's target area, i.e., a historical and cultural city with a highly dense population.

The highest economic benefit provided by UGI in the core capital region of Beijing was generated from carbon sequestration and oxygen production ( $46.32 \%$ of the total), followed by climate regulation benefits $(31.41 \%)$, and cultural service benefits $(21.28 \%)$. In recent studies of a larger scale, provisional services always contributed the majority of the local ES value, since larger swaths of land are used for food and materials production $[26,57]$. Unlike prior studies, we adopted a more suitable ES evaluation system for an urban environment to estimate the true value of UGI in high-density areas that do not contain a lot of productive farms or grasslands.

Our findings were similar to other urban-context evaluations, where the largest ES value that urban ecosystems provide is through carbon sequestration and oxygen production $[26,41]$, as well as other climate regulation benefits. The monetary value generated through air pollution control alone, at CNY $¥ 8,075,575$ in our case study, was higher than previous studies from Guangzhou (CNY ¥901,900) [26], regardless of their similarities in density and historical context. The different values on the axes of air pollution control were caused by different standards in processing costs for $\mathrm{SO}^{2}$ in each region. Our result was, therefore, in line with the $\mathrm{SO}^{2}$ processing costs listed by the current evaluation report on the cost of municipal solid waste incineration in Beijing [58]. Finally, the estimated total ES value generated for each individual from local UGI in the capital core area of Beijing (CNY ¥91.76 per capita) was lower than the per capita value found in studies from other metropolises across China, for instance, Shenzhen, which recorded an ES value of CNY $¥ 7205.4$ per capita [40] in 2005. Built within the last 40 years, Shenzhen city owned a much 
higher ratio of green space per capita $\left(16.1 \mathrm{~m}^{2}\right)$ [40] than the core area of Beijing $\left(6.37 \mathrm{~m}^{2}\right)$. This result indicated that green space areas might directly contribute to human wellbeing in the surrounding area. This differs from the small proportion of cultural services in other ecosystems of some previous studies [57]. Our result indicated that cultural services also contributed a large percentage of the total economic value of ES $(21.8 \%)$ provided by the UGI system in the area with rich historical and tourism resources. These results were in line with the values estimated by Li et al. (2012) per the cultural ecosystem values for green spaces in Beijing.

Our study further differentiated itself from other research in this field via its focus on the functional assessments of cultural services [59]. For instance, our study first incorporated cultural services into a total economic value estimation that contrasts other ecosystem services in an urban context. As such, our result also intuitively addressed UGI contributions in favor of resident wellbeing on a spiritual dimension via the quantification of these (sometimes intangible) cultural services.

Our analysis provided additional insight into ES value distributions as provided by UGI in different communities. Our results addressed even those communities where UGI generates lower ES value-information that has the potential to support urban decisionmakers and urban planners as they work to understand the contributions that UGI may have for urban ecosystems. The intent for these stakeholders would be to identify potential directions for green space planning strategies in those communities with lower ES values and to engage differing development perspectives.

Our resultant per-community distribution of total ES value was directly affected by the land cover of local UGI. This effect may be explained by previous studies [60], which address proxies (e.g., estimates of service for a particular land cover type) that are frequently used to examine the distribution and congruence of ecosystem services. Our results also indicated that the distribution of various single ES values within each community are closely related to the total area of forest and grassland since tree cover constitutes a simple and effective way to establish climate regulation, carbon sequestration and oxygen production, noise reduction, and air pollution reduction. The efficiency of atmospheric cleansing by trees in congested Chinese cities could therefore be improved by planting more trees as opposed to simple shrubs or grass to diversify species composition and biomass structure, and to provide sound green space management. The implications for greenery design were discussed with a view of maximizing this ecosystem service in Chinese cities and other developing metropolises. Similar findings have been confirmed by the booming ES value evaluations found in prior studies of other ecosystem types [26,61,62].

Scholars have long known that vegetative height and leaf traits (i.e., dry leaf matter) were response mechanisms that strongly influence a land's use and abiotic environment, with follow-up effects on surrounding ecosystem properties. Such traits could therefore be used as functional markers of the aforementioned ES values. Moreover, since only one assessment exists per CES in Beijing's central, historical district [63], we addressed individual communities located at different geographical and demographic intersections throughout Beijing and found they provide the highest CES value due to their high-density heritage make-up and the recreational centers and streets which occupy the area. The public survey portion of our study addressed, for example, that the Niujie community, which provided the highest cultural service value due to a strong sense of cultivated belonging between the residents of its close-knit Muslim community. However, the distribution of the CES values generated by UGI in our result did differ from the CES rates produced by the more built-up areas known to central Beijing, at least from a public perspective. In this context, our results revealed a distribution of UGI cultural service values at the community level to address community specifics. For instance, communities like Tiantan, Longtan, and Shichahai have the largest urban park areas (such as the Temple of Heaven historical park and Shichahai park) and possess the highest cultural service value as a direct result of UGI. The differences in these findings may be explained by previous studies on the impact of 
land cover proxies, and how when used, would often not fit well with primary qualitative data such as public preferences [60].

However, there may be some limitations in this study. Our CES assessment is based on the general CES value provided by green spaces per hectare in Beijing because of data accessibility. For our cultural services assessment, data collection has always been a difficult point since there are many types of cultural service products. Furthermore, usable objective data for value calculations as a direct result of cultural services are hard to collect. The value of each kind of cultural service product, i.e., recreation, tourism, and aesthetic and cultural heritage, remain to be explored. Deeper research is needed to evaluate each CES separately. For instance, outdoor leisure, recreation, and the cultural heritage values that result from UGI could be assessed via a person's willingness to pay for travel or living costs, determined with the travel cost method (TCM) or the hedonic pricing method (HPM) [64,65]. Moreover, the beneficial mental and physical health effects that come as a result of direct contact with a natural environment can be valued in monetary terms and via health-related quality of life indicators. Further studies will require more public participation surveys to determine local resident perceptions and will need to consult socialeconomic demographics (like property prices on the local housing market) to establish a truly detailed CES assessment.

A final limitation of this study relates to the generalizability of our results is the feature of our case study area; certainly, the capital core area in Beijing is the most population-dense city in China. It is, therefore, still unclear whether factors like city scale and context (i.e., UGI benefits in larger or smaller, or older or newer cities) will impact the consistency of the ES value resulting from UGI. These unknown considerations may limit our ability to generalize our results to other, smaller cities. Thus, an exploration of UGI's most common ES features across different urban contexts and scales could be a future avenue of significant study on this topic.

\section{Conclusions}

Our study assessed the economic value of ecosystem services (ES) provided by UGI in the capital core region of Beijing, one of the most high-density, long-standing areas in China. In this study, we established the economic value of these services across six ES types, including climate regulation, carbon sequestration and oxygen production, water control and conservation, noise reduction, air pollution reduction, and cultural services. From our results, we concluded that UGI in the capital core area of Beijing generates an annual ecosystem service value of approximately CNY $¥ 1,561,152,227$. This was a significant fiscal impact that all policymakers must recognize and incorporate into their future urban planning and management decisions.

At the community level for this target area, we also indicated a distribution pattern for ES values. We addressed the trend of how UGI, located in and around the communities along the south-central Chang'an Road, provided the lowest ecosystem service values and considered why they may demand more investment and planning strategies from local UGI projects. The findings of our study also have greater policy implications in terms of understanding the current ES values that exist within the capital core area of Beijing, as well as assessing the development of future strategic planning of local UGI.

To close out this paper, we have provided a few recommendations which naturally emerge from this research:

1. Diversify greenery designs. As tree cover closely affects various kinds of ES values, the ES efficiencies generated by ethical UGI in congested Chinese urban contexts could be improved by planting more trees (other than shrubs or grass), diversifying species composition and biomass structure, and providing sound green space management.

2. Promote public participation for alternative public green space management at the community level. The benefit of the total CES value provided by other public green spaces could be improved via increased participation of residents, often accomplished 
when various aspects of CES are improved, including a local sense of belonging, social connection, and recreational activity.

3. Increase investment in micro-green spaces in communities with lower ES values. This measure may enhance the total UGI area of high-density historical regions in an urban context, as well as improve the accessibility of residents nearby, all to alleviate an existing, non-equal distribution of green space resources. The overall intent and results must contribute to and improve resident wellbeing in the target surrounding area.

Author Contributions: Conceptualization, H.X.; methodology, G.Z.; software, G.Z.; validation, H.X.; formal analysis, G.Z.; resources, H.X.; data curation, H.X.; writing—original draft preparation, H.X.; writing—-review and editing, H.X. and G.Z.; visualization, G.Z.; project administration, H.X. All authors have read and agreed to the published version of the manuscript.

Funding: This research received the support from the funding of young scholar development project in BUCEA.

Institutional Review Board Statement: Not applicable.

Informed Consent Statement: Not applicable.

Data Availability Statement: Not applicable.

Conflicts of Interest: The authors declare no conflict of interest.

\section{Appendix A}

Table A1. Below are the basic parameters, methods, and data sources used in this study to estimate the annual value of major ecosystem services, as generated by UGI in central Beijing.

\begin{tabular}{|c|c|c|c|}
\hline Ecosystem Service & Evaluation Method & Description of Annual Value Estimate & Sources \\
\hline & & $\begin{array}{l}\text { Climate regulation Equation (1): } \\
\text { Annual benefit }=\text { Area of forestland } \times \text { Amount of trees } \\
\text { per hectare for forestland } \times \text { Amount of air } \\
\text { conditioners provided same Climate same benefits as } \\
\text { one tree } \times \text { air conditioners working hours per day } \times \\
\text { air conditioners working days per year } \times \text { the } \\
\text { economic value of power consumption of each air } \\
\text { conditioner per hour. }\end{array}$ & \\
\hline Climate regulation & Replacement cost method & $\begin{array}{l}\text { - Amount of trees per hectare for forestland }=100 \\
\text { - } \quad \text { Amount of air conditioners provided same } \\
\text { - } \quad \text { Air conditioner working hours per day }=20 \mathrm{~h} \\
\text { - } \quad \text { The economitioners volue of power consumption of } \\
\text { each air conditioner per hour }=\mathrm{CNY} \\
0.516 /(\mathrm{h} \cdot \text { unit })\end{array}$ & {$[34,36,41]$} \\
\hline
\end{tabular}


Table A1. Cont.

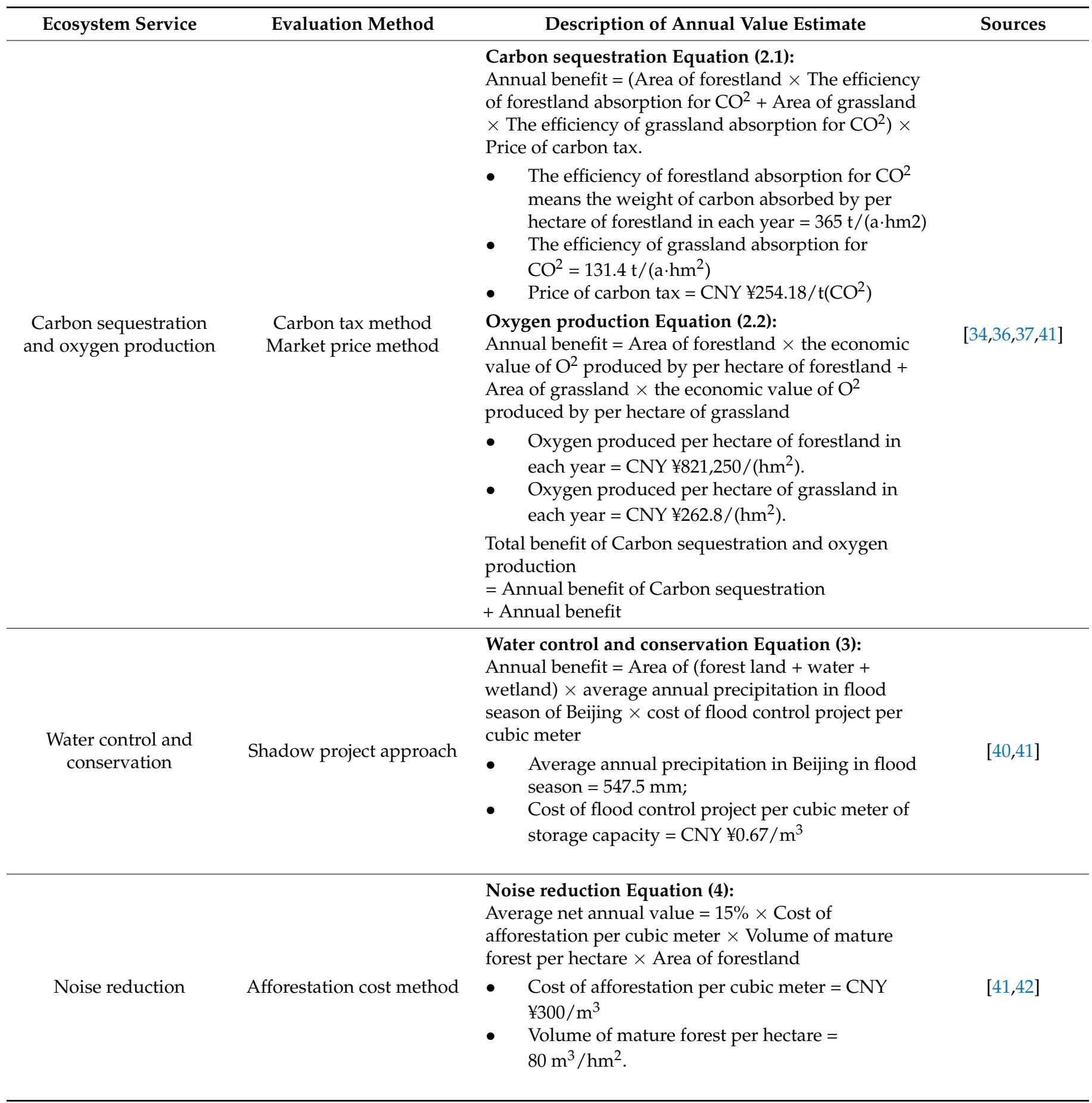


Table A1. Cont.

\begin{tabular}{|c|c|c|c|}
\hline Ecosystem Service & Evaluation Method & Description of Annual Value Estimate & Sources \\
\hline Air pollution reduction & Replacement cost method & 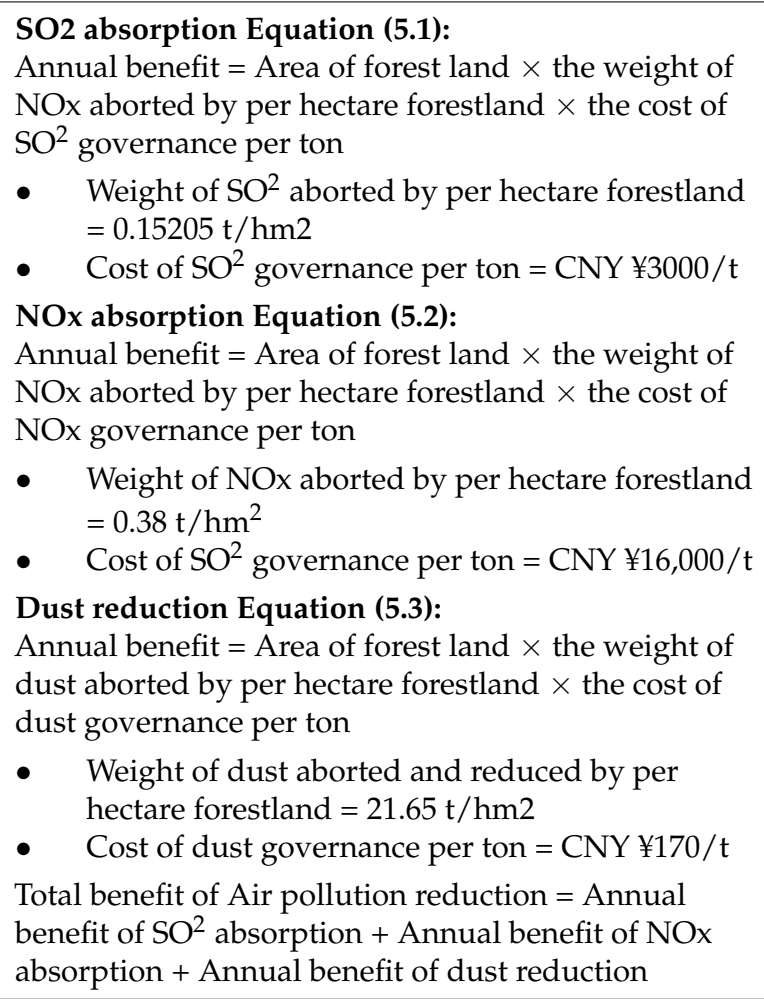 & {$[34,36,43]$} \\
\hline Cultural service & Market Price Method & $\begin{array}{l}\text { Cultural service Equation (6): } \\
\text { Average net annual value }=\text { Area of each kind of green } \\
\text { space } \times \text { value of CES provided by each type of green } \\
\text { space in Beijing } \\
\text { - } \quad \text { CES provided by Park in Beijing = CNY } \\
\quad ¥ 27.24 / \mathrm{m}^{2} \\
\text { - CES provided by other public green space in } \\
\quad \text { Beijing }=\text { CNY } ¥ 16.70 / \mathrm{m}^{2}\end{array}$ & [46] \\
\hline
\end{tabular}

\section{References}

1. Ahern, J. Green infrastructure for cities: The spatial dimension. In Cities of the Future: Towards Integrated Sustainable Water and Landscape Management, 17th ed.; IWA Publishing: London, UK, 2007; pp. 267-283. [CrossRef]

2. Benedict, M.; McMahon, E. Green Infrastructure: Linking Communities and Landscapes, 1st ed.; Island Press: Washington, DC, USA, 2006; pp. 1-3.

3. Mell, I.C.; Henneberry, J.; Helh-Lange, S.; Keskin, B. To green or not to green: Establishing the economic value of green infrastructure investments in The Wicker, Sheffield. Urban For. Urban Green. 2016, 18, 257-267. [CrossRef]

4. Tzoulas, K.; Korpela, K.; Venn, S.; Yli-Pelkonen, V.; Kaźmierczak, A.; Niemela, J.; James, P. Promoting ecosystem and human health in urban areas using Green Infrastructure: A literature review. Landsc. Urban Plan. 2007, 81, 167-178. [CrossRef]

5. Van Oijstaeijen, W.; Van Passel, S.; Cools, J. Urban green infrastructure: A review on valuation toolkits from an urban planning perspectives. J. Environ. Manag. 2020, 267, 301-479. [CrossRef]

6. Herath, H.M.P.I.K.; Halwatura, R.U.; Jayasinghe, G.Y. Evaluation of green infrastructure effects on tropical Sri Lankan urban context as an urban heat island adaptation strategy. Urban For. Urban Green. 2018, 29, 212-222. [CrossRef]

7. Russo, A.; Chan, W.T.; Cirella, G.T. Estimating air pollution removal and monetary value for urban green infrastructure strategies using web-based applications. Land 2021, 10, 788. [CrossRef]

8. Cortinovis, C.; Zulian, G.; Geneletti, D.J.L. Assessing nature-based recreation to support urban green infrastructure planning in Trento (Italy). Land 2018, 7, 112. [CrossRef]

9. Nazir, N.N.M.; Othman, N.; Nawawi, A.H. Green infrastructure and its roles in enhancing quality of life. Procedia Soc. Behav. Sci. 2014, 153, 384-394. [CrossRef] 
10. Liu, L.; Jensen, M.B.J.C. Green infrastructure for sustainable urban water management: Practices of five forerunner cities. Cities 2018, 74, 126-133. [CrossRef]

11. Jaeger, J.A.; Soukup, T.; Schwick, C.; Madrinan, L.; Kienast, F. Landscape Fragmentation in Europe, in European Landscape Dynamics; CRC Press: Boca Raton, FL, USA, 2016; pp. 187-228. [CrossRef]

12. Abhijith, K.; Kumar, P.; Gallagher, J.; McNabola, A.; Baldauf, R.; Pilla, F.; Broderick, B.; Sabatino, S.; Pulvinrenti, B. Air pollution abatement performances of green infrastructure in open road and built-up street canyon environments-A review. Atmos. Environ. 2017, 162, 71-86. [CrossRef]

13. Chatzimentor, A.; Apostolopoulou, E.; Mazaris, A. A review of green infrastructure research in Europe: Challenges and opportunities. Landsc. Urban Plan. 2020, 198, 103775. [CrossRef]

14. Pauleit, S.; Ambrose-Oji, B.; Andersson, E.; Anton, B.; Buijs, A.; Haase, D.; Elands, B.; Hansen, R.; Kowarik, I.; Kronenberg, J.; et al. Advancing urban green infrastructure in Europe: Outcomes and reflections from the GREEN SURGE project. Urban For. Urban Green. 2019, 40, 4-16. [CrossRef]

15. Millennium Ecosystem Assessment Board. Ecosystems and Human Well-Being, 5th ed.; Island Press: Washington, DC, USA, 2005; pp. 10-11. Available online: https://islandpress.org/books/ecosystems-and-human-well-being (accessed on 2 November 2021).

16. Miller, J.R.; Hobbs, N. Recreational trails, human activity, and nest predation in lowland riparian areas. Landsc. Urban Plan. 2000, 50, 227-236. [CrossRef]

17. Connelly, N.A.; Knuth, B.A.; Kay, D. Public support for ecosystem restoration in the Hudson River Valley, USA. Environ. Manag. 2002, 29, 467-476. [CrossRef] [PubMed]

18. Chon, J.; Scott, C. Aesthetic responses to urban greenway trail environments. Landscape. Res. 2009, 34, 83-104. [CrossRef]

19. McPhearson, T.; Hamstead, Z.A.; Kremer, P.J.A. Urban ecosystem services for resilience planning and management in New York City. Ambio 2014, 43, 502-515. [CrossRef] [PubMed]

20. De Groot, R.S.; Alkemade, R.; Braat, L.; Hein, L.; Willenmen, L. Challenges in integrating the concept of ecosystem services and values in landscape planning, management and decision making. Ecol. Complex. 2010, 7, 260-272. [CrossRef]

21. Amorim, J.H.; Engardt, M.; Johansson, C.; Ribeiro, I.; Sannebro, M. Regulating and Cultural Ecosystem Services of Urban Green Infrastructure in the Nordic Countries: A Systematic Review. Int. J. Environ. Res. Public Health 2021, 18, 1219. [CrossRef] [PubMed]

22. Kumar, P. The Economics of Ecosystems and Biodiversity: Ecological and Economic Foundations; Routledge Press: London, UK, 2012; pp. 127-185. [CrossRef]

23. Maes, J.; Liquete, C.; Teller, A.; Erhard, M.; Paracchini, M.L.; Barredo, J.I.; Grizzetti, B.; Cardoso, A.; Somma, F.; Petersen, J.E.; et al. An indicator framework for assessing ecosystem services in support of the EU Biodiversity Strategy to 2020. Ecosyst. Serv. 2016, 17, 14-23. [CrossRef]

24. Gómez-Baggethun, E.; Barton, D.N. Classifying and valuing ecosystem services for urban planning. Ecosyst. Economy. 2013, 86, 235-245. [CrossRef]

25. Common International Classification of Ecosystem Services (CICES). Available online: www.cices.eu (accessed on 24 August 2021).

26. Yin, S.; Shen, Z.; Zhou, P.; Zou, X.; Che, S.; Wang, W. Quantifying air pollution attenuation within urban parks: An experimental approach in Shanghai, China. Environ. Pollut. 2011, 159, 2155-2163. [CrossRef]

27. Wang, Y.; Shen, J.K.; Xiang, W.N. Ecosystem service of green infrastructure for adaptation to urban growth: Function and configuration. Ecosyst. Health Sustain. 2018, 4, 132-143. [CrossRef]

28. Jia., H.; Dai., F. Review on the development of green infrastructure research in China. Landscape. Archit. 2015, 8, 118-124.

29. Bi, L.; Chen, W.; Xin, W. Research Progress of Green Infrastructure. Acta Ecol. Sin. 2017, 37, 5246-5261.

30. Regulatory Detailed Planning for the Functional Core Area of the Capital (2018-2035). Available online: http:/ / www.beijing.gov. cn/gongkai/guihua/wngh/cqgh/202008/W020200902354838202786.pdf (accessed on 24 August 2021).

31. Gong, P.; Liu, H.; Zhang, M.; Li, C.; Wang, J.; Huang, H.; Clinton, N.; Ji, L.; Li, W.; Bai, Y.; et al. Stable classification with limited sample: Transferring a 30-m resolution sample set collected in 2015 to mapping 10-m resolution global land cover in 2017. Sci. Bull. 2019, 64, 370-373. [CrossRef]

32. Li, C.; Gong, P.; Wang, J.; Zhu, Z.; Biging, G.S.; Yuan, C.; Hu, T.; Zhang, H.; Wang, Q.; Li, X.; et al. The first all-season sample set for mapping global land cover with Landsat-8 data. Sci. Bull. 2017, 62, 508-515. [CrossRef]

33. Costanza, R.; D’Arge, R.; de Groot, R.; Farber, S.; Grasso, M.; Hannon, B.; Limburg, K.; Naeem, S.; O’Neill, R.V.; Paruelo, J.M.; et al. The value of the world's ecosystem services and natural capital. Nature 1997, 387, 253-260. [CrossRef]

34. Knapp, S.; Jaganmohan, M.; Schwarz, N. Climate regulation by diverse urban green spaces: Risks and opportunities related to climate and land use change. In Atlas Ecosystem Services; Springer: Berlin/Heidelberg, Germany, 2019; pp. 167-172. [CrossRef]

35. Monteiro, M.V.; Doick, K.J.; Handley, P.; Peace, A. The impact of greenspace size on the extent of local nocturnal air temperature cooling in London. Urban For. Urban Green. 2016, 16, 160-169. [CrossRef]

36. Pauleit, S.; Liu, L.; Ahern, J.; Kazmierczak, A. Multifunctional green infrastructure planning to promote ecological services in the city. In Urban Ecology. Patterns, Processes, and Applications; Oxford University Press: Oxford, UK, 2011; pp. 272-285. [CrossRef]

37. Sinnett, D.; Smith, N.; Burgess, S. Handbook on Green Infrastructure: Planning, Design and Implementation, 1st ed.; Edward Elgar Publishing: Cheltenham, UK, 2015; pp. 100-105. [CrossRef]

38. Saaroni, H.; Amorim, J.H.; Hiemstra, A.; Pearlmutter, D. Urban Green Infrastructure as a tool for urban heat mitigation: Survey of research methodologies and findings across different climatic regions. Urban Clim. 2018, 24, 94-110. [CrossRef] 
39. Hewitt, C.N.; Ashworth, K.; MacKenzie, A. Using green infrastructure to improve urban air quality (GI4AQ). Ambio 2020, 49, 62-73. [CrossRef] [PubMed]

40. Peng., J.; Wang, Y.; Chen, Y.; Li, W.; Jiang, Y. Economic Value of Urban Ecosystem Services: A Case Study in Shenzhen. J. Peking Univ. 2005, 4, 594-604.

41. Technical Guidelines for Urban Forest Construction (DB11/T 1637-2019). 2019. Available online: http://yllhj.beijing.gov.cn/ zwgk/fgwj/dfbz/201911/t20191130_765472.shtml (accessed on 25 August 2021).

42. Li, T.; Gao, X.J.W. Ecosystem services valuation of lakeside wetland park beside Chaohu Lake in China. Water $2016,8,301$. [CrossRef]

43. Harrison, P.A.; Dunford, R.; Barton, D.N.; Kelemen, E.; Martin-Lopez, B.; Norton, L.; Termansen, M.; Saarikoski, H.; Hendriks, K.; Gómez-Baggethun, E.; et al. Selecting methods for ecosystem service assessment: A decision tree approach. Ecosyst. Serv. 2018, 29, 481-498. [CrossRef]

44. Ecosystem Valuation. 2000. Available online: https://www.ecosystemvaluation.org/market_price.htm (accessed on 25 August 2021).

45. 2020 China Carbon Pricing Survey. 2020. Available online: http://www.chinacarbon.info/wp-content/uploads/2020/12/2020 -CCPS-EN.pdf (accessed on 25 August 2021).

46. Liu, L.; Fryd, O.; Zhang, S. Blue-Green Infrastructure for Sustainable Urban Stormwater Management-Lessons from Six Municipality-Led Pilot Projects in Beijing and Copenhagen. Water 2019, 11, 2024. [CrossRef]

47. Rainfall in Beijing of Beijing Meteorological Service. Available online: http://bj.cma.gov.cn/xwzx/mtjj/201609/t20160929_6141 31.html (accessed on 24 August 2021).

48. Wu, J.; You, Y. Preliminary Assessment of Ecosystem Services Value of Pearl River Delta Greenway Line One. China. Landscape. Archit. 2017, 33, 98-103.

49. Francis, C.D.; Kleist, N.; Ortega, C.P.; Cruz, A. Noise pollution alters ecological services: Enhanced pollination and disrupted seed dispersal. Proc. R Soc. B Biol. Sci. 2012, 279, 2727-2735. [CrossRef]

50. Margaritis, E.; Kang, J. Relationship between green space-related morphology and noise pollution. Ecol. Indic. 2016, 72, 921-933. [CrossRef]

51. Dickinson, D.C.; Hobbs, R. Cultural ecosystem services: Characteristics, challenges and lessons for urban green space research. Ecosyst. Serv. 2017, 25, 179-194. [CrossRef]

52. Xu, H.; Zhao, G.; Fagerholm, N.; Primdahl, J.; Plieninger, T. Participatory mapping of cultural ecosystem services for landscape corridor planning: A case study of the Silk Roads corridor in Zhangye, China. J. Environ. Manag. 2020, 264, 110458. [CrossRef] [PubMed]

53. Riechers, M.; Barkmann, J.; Tscharntke, T. Perceptions of cultural ecosystem services from urban green. Ecosyst. Serv. 2016, 17, 33-39. [CrossRef]

54. Li, X.; Lei, S.; Feng, J.; Wen, Y. Evaluation on the cultural service value of the green spaces in Beijing. J. Arid Land Resour. Environ. 2019, 6, 33-39.

55. Xie, G.; Zhang, C.; Zhang, C.; Xiao, Y.; Lu, C. The value of ecosystem services in China. Resour. Sci. 2015, 37, 1740-1746.

56. Ouyang, Z.; Xin, W. A Preliminary Study on the Service Function of China's Terrestrial Ecosystem and Its Eco-economic Value. Acta Ecol. Sin. 1999, 19, 607-613.

57. Sharma, B.; Rasul, G.; Chettri, N.J. The economic value of wetland ecosystem services: Evidence from the Koshi Tappu Wildlife Reserve, Nepal. Ecosyst. Serv. 2015, 12, 84-93. [CrossRef]

58. Beijing Municipal Solid Waste Incinerator Meeting Cost Assessment Report. Available online: http://nads.ruc.edu.cn/upfile/ file/20170322152504_900619_56051.pdf (accessed on 24 August 2021).

59. Zhang, X.; Xie, H.; Shi, J.; Lv, T.; Zhou, C.; Liu, W.D. Assessing changes in ecosystem service values in response to land cover dynamics in Jiangxi Province, China. Int. J. Environ. Res. Public Health 2020, 17, 3018. [CrossRef]

60. Eigenbrod, F.; Armsworth, P.R.; Anderson, B.J.; Heinemeyer, A.; Gillings, S.; Roy, D.B.; Gaston, K.J. The impact of proxy-based methods on mapping the distribution of ecosystem services. J. Appl. Ecol. 2010, 47, 377-385. [CrossRef]

61. Jim, C.; Chen, W.Y. Assessing the ecosystem service of air pollutant removal by urban trees in Guangzhou (China). J. Environ. Manag. 2008, 88, 665-676. [CrossRef] [PubMed]

62. Windhager, S.; Steiner, F.; Simmons, M.T.; Heymann, D. Toward ecosystem services as a basis for design. Landsc. J. 2010, 29, 107-123. [CrossRef]

63. Zhen, S.; Ma, M.; Li, H.; Wang, J.; Zhang, L. Evaluation of Ecological Space Cultural Services in Urban Central Districts from the Perspective of Residents' Welfare-Take Beijing as an example. Urban Stud. 2021, 28, 21-27.

64. Sinclair, M.; Mayer, M.; Woltering, M.; Ghermandi, A. Valuing nature-based recreation using a crowdsourced travel cost method: A comparison to onsite survey data and value transfer. Ecosyst. Serv. 2020, 45, 101165. [CrossRef]

65. Sander, H.A.; Haight, R.G. Estimating the economic value of cultural ecosystem services in an urbanizing area using hedonic pricing. J. Environ. Manag. 2012, 113, 194-205. [CrossRef] 